\title{
O Enfoque de Risco na Programação em Saúde
}

\section{Chester Luiz Galvão Cesar*}

O painel - O Enfoque de Risco na Programação em Saúde - debateu com os participantes três trabalhos, apresentados pelos coordenador e pelos expositores.

O primeiro texto, do Prof. Chester - O Enfoque de Risco na Programação em Saúde - situou a proposta da "estratégia de risco" na programação materno infantil, apresentando sucintamente sua fundamentação, comentando as atividades desenvolvidas pelo Ministério da Saúde na década de oitenta e algumas experiências desenvolvidas no Estado de São Paulo. Foram também citadas algumas críticas relativas a esta proposta da OMS, concluindo pela importância de levá-las em consideração na implantação de programas com enfoque de risco.

O segundo texto apresentado e discutido foi o do Prof. José Ricardo, que após relatar a origem da proposta de "Enfoque de Risco" (Risk Approach RA), comentou criticamente a proposta e a própria incorporação do conceito de risco pelos serviços de saúde. A seguir, fez algumas considerações sobre programação em saúde, concluindo pela necessidade de rever a relação entre risco e programação.

Finalmente a Dra. Valéria V. Lima apresentou e discutiu uma avaliação dos serviços de saúde de Lins e Penápolis, municípios do interior do estado de São Paulo. A avaliação baseou-se principalmente na análise de mortes evitáveis, em dois períodos, 1979-1981 e 1990-1992. Além das questões metodológicas a expositora enfatizou a oportunidade que o processo de descentralização dos serviços de saúde e particularmente a municipalização vem trazendo para a "experimentação de propostas transformadoras em direção às necessidades de saúde da população e à viabilização do Sistema Único de Saúde".

\footnotetext{
* Professor Doutor do Departamento de Epidemiologia da Faculdade de Saúde Pública da USP.
} 
O painel no seu conjunto de exposições e discussões, permitiu rever conceitos e fundamentos do "enfoque de risco" na programação em saúde, bem como analisar uma experiência recente de municipalização de serviços de saúde, avaliada através de um estudo comparativo de óbitos evitáveis, em dois municípios em dois diferentes períodos.

\section{O Enfoque de Risco na Programação em Saúde}

Os programas de saúde tradicionalmente desenvolvidos pelo setor público, e particularmente os programas desenvolvidos pela Secretaria de Estado da Saúde de São Paulo, a partir de meados da década de setenta, caracterizaramse como programas normativos, com atividades e metas definidas para o atendimento da clientela da rede de unidades básicas de saúde - Centros de Saúde.

A assistência prestada ao grupo materno-infantil baseava-se também nesta linha de programação, e pouca ênfase era dada em diferenciar a clientela quanto aos riscos aos quais estavam expostos os diferentes pacientes, e que expressavam a necessidade em saúde específica de cada um deles. Embora estivesse implícita a possibilidade de adaptação dos programas às realidades locais, isto refletia-se muito mais em uma adaptação às disponibilidades de recursos, do que às características das gestantes e crianças inscritas nos diversos serviços. A própria avaliação dos programas baseava-se, em grande parte, no cumprimento de metas, como número médio de consultas por gestante ou por criança, idade gestacional média à primeira consulta, exames solicitados, etc.

O processo de descentralização dos serviços de saúde através da municipalização, bem como a proposta de criação de Distritos Sanitários, levou à necessidade de um conhecimento mais detalhado dos diferenciais de saúde, não só definidos através do espaço geográfico - diferentes perfis de saúde nas diversas áreas de um mesmo município - como também através dos "fatores de risco" aos quais as diferentes famílias estavam expostas. Esses diferenciais, e a identificação de situações de risco, quer biológico, ambiental ou sócio-cultural às quais estão expostas os diferentes grupos populacionais, vêm tendo uma importância crescente na organização dos sistemas locais de saúde.

No final da década de setenta e início da de oitenta, a Organização Mundial de Saúde - OMS, divulgou documentos ${ }^{(2,5,10)} \mathrm{em}$ que propunha a "programação materno-infantil com enfoque de risco" como um dos instrumentos para alcançar a meta de "Saúde para todos no ano 2000". Esses documentos foram a seguir incorporados em programas de treinamento em diversos países ${ }^{(7,89)}$, inclusive no Brasil.

A "estratégia de risco" fundamenta-se na diferença de incidências de eventos desfavoráveis (doença e óbito) nos diversos grupos populacionais com "características próprias ou sujeitos a circunstâncias específicas (fatores de risco)". A existência destes "fatores de risco" e a possibilidade de sua identifi- 
cação antes da ocorrência da doença ou óbito (dano) abria a possibilidade, segundo a posposta da OMS, de evitá-los ou de compensar a sua presença através de ações de saúde.

A implantação de uma programação com enfoque de risco deve seguir algumas etapas, iniciando-se com a identificação dos agravos à saúde prioritários e a identificação dos fatores de risco para estes agravos. A seguir, devem ser identificados os grupos expostos a esses fatores de risco e que devam receber uma assistência diferenciada. A organização e o funcionamento dos serviços de saúde devem, então ser analisados, quanto à sua adequação em responder às necessidades desses grupos de maior risco. Finalmente é necessário acompanhamento e avaliação dos programas, para possíveis correções.

Um ponto importante na implantação da estratégia de risco, consiste na definição ou no desenvolvimento de "instrumentos preditivos", para identificação dos grupos de alto risco. A proposta da OMS sugere diferentes possibilidades, desde metodologias qualitativas - como o método Delphos - até a elaboração de escalas numéricas baseadas em valores de riscos relativos ${ }^{3)}$.

Embora o Ministério da Saúde tenha promovido, na década de setenta, vários treinamentos para a "programação materno-infantil com enfoque de risco", esta estratégia não chegou a ser amplamente implantada nos órgãos oficiais de saúde. No Estado de São Paulo, dois municípios, entre outros, destacaram-se pela implantação da proposta: Bauru, com o programa intitulado "Programa de Defesa da Vida dos Lactentes" (6) e mais recentemente o município de Santos.

A estratégia de risco proposta pela OMS tem sido alvo de críticas: com relação à forma como trabalha as variáveis sociais ${ }^{(1,4)}$; pelos critérios, muitas vezes subjetivos e pouco precisos, para a definição dos grupos de alto risco (1);ela distorção que sua aplicação pode trazer em definir os grupos de risco, como população alvo para planejamento familiar ${ }^{(1)}$; e mesmo algumas críticas a sua própria fundamentação teórica ${ }^{(4)}$.

Essas críticas talvez não invalidem a proposta, porém são importantes por alertarem para os seus limites e para os cuidados a serem tomados na sua implantação.

\section{Referências Bibliográficas}

1. ALVARENGA, A.T. O enfoque de risco. In: Seminário Estadual de Saúde da Criança 20, São Paulo, 1986. Anais. São Paulo. Governo do Estado de São Paulo, Secretaria de Estado da Saúde, 1987, p.19-24.

2. BACKETT, E. M.; DAVIES, A. M.; PETROS-BARVAZIAN, A. The risk approach in health care. Geneva, World Health Organization, 1984. (WHO - Public Health Papers, 76). 
3. CESAR, C. L. G. Fatores de risco associados à mortalidade infantil em duas áreas da região metropolitana de São Paulo (Brasil), 1984-1985. Proposta de instrumentos preditivos. Rev. Saúde Pública, 24:300-10, 1990.

4. HAYES, M. V. The risk approach: unassailable logic? Soc. Sci. Med., 33:55-70, 1991.

5. ORGANIZACION MUNDIAL DE LA SALUD. Metodo de atencion sanitária de la madre y el niño basado en el concepto de riesgo. Ginebra, 1978. (OMS. Publicación en offset no 39).

6. RUMEL, D. et al. Acurácia dos indicadores de risco do Programa de Defesa da Vida do Lactente em região do Estado de São Paulo, Brasil. Rev. Saúde Pública., 26:6-11, 1992.

7. SECRETARIA DE ESTADO DA SAÚDE DE SÃO PAULO. Seminário de aplicação do enfoque de risco na organização de serviços de saúde. Sorocaba, 1984. 2v.

8. MINISTÉRIO DA SAÚDE/ORGANIZAÇÃO PANAMERICANA DA SAÚDE. Seminário nacional de aplicação do enfoque de risco na organização de serviços de saúde, Brasília, 1983. 5v.

9. WORLD HEALTH ORGANIZATON. A work book ou how to plan and carry out research ou the risk approach in maternal and child health including family planning. Geneva, Division of Family Health, 1984 (Experimental edition FHE/MCH/RA 84.1).

10. WORLD HEALTH ORGANIZATION. Risk approach for maternal and child health: a selected, annotated bibliography. Geneva, Division of Family Health, 1981. 